\title{
Attachment of Alanine and Arginine to the Ge(100)-2×1 Surface
}

\author{
Pendar Ardalan, Nazanin Davani, and Charles B. Musgrave* \\ Department of Chemical Engineering, Stanford University, Stanford, California 94305
}

Received: July 24, 2006; In Final Form: November 9, 2006

\begin{abstract}
The reactions of the amino acids alanine and arginine on the Ge(100)- $2 \times 1$ surface are investigated using density functional theory. Arginine presents a unique reactivity not previously explored on semiconductor surfaces. Arginine dative bonds to the surface dimer through its imine lone pair, resulting in two adsorbed conformations with adsorption energies of 30.7 and $33.8 \mathrm{kcal} / \mathrm{mol}$, significantly stronger than amine dative bonds on $\mathrm{Ge}(100)-2 \times 1$. We predict a $\mathrm{N}-\mathrm{H}$ dissociation and an ene reaction pathway from each of these two conformers with the ene reactions kinetically favored over $\mathrm{N}-\mathrm{H}$ dissociation of the imine $\mathrm{N}-\mathrm{H}$ bond and the ene reaction from the cis state favored both kinetically and thermodynamically over the trans ene reaction. Our results for the reactions of the hydroxyl, carbonyl, and amine functional groups are similar to previous observations for analogous reactions of small organic molecules on $\mathrm{Ge}(100)-2 \times 1$. We find that $\mathrm{O}-\mathrm{H}$ dissociation from the carbonyl dative bonded state is the most favorable pathway. The amine dative bonded state is slightly more stable than the carbonyl dative bonded state. We find that [2+2] cycloaddition through the $\mathrm{C}=\mathrm{N}$ double bond is exothermic by only $3.3 \mathrm{kcal} / \mathrm{mol}$.
\end{abstract}

\section{Introduction}

A growing body of experimental and theoretical studies has investigated the organic functionalization of semiconductor substrates motivated by potential applications in molecular electronics, sensors, and hybrid organic-semiconductor electronic and optical devices. ${ }^{1-5}$ Although many organic reactions on the $\mathrm{Si}(100)-2 \times 1$ surface have been examined, fewer have been explored on the $\mathrm{Ge}(100)-2 \times 1$ surface. Furthermore, although the set organic functional groups whose reactivity has been explored on semiconductor surfaces is now quite extensive, many organic functional groups are yet to be examined.

Previous studies of organic reactions on the $\mathrm{Si}(100)-2 \times 1$ and Ge(100)- $2 \times 1$ surfaces prepared in ultrahigh vacuum (UHV) show that these surfaces are highly reactive toward a wide variety of organic functional groups. The reactivity is attributed to the nature of the clean group IV (100)- $2 \times 1$ reconstructed surfaces, which consist of rows of tilted dimers. ${ }^{6-9}$ The tilting of the dimers results in their zwitterionic character where the "up" atom is an electron rich nucleophile and the "down" atom is an electron poor electrophile, thus explaining the tendency of dimers to react through nucleophilic and electrophilic mechanisms. Furthermore, the weak $\pi$-bond between the two surface dimer atoms makes the dimer appear as a reactive olefin that is active toward olefinic reactions, such as cycloadditions. ${ }^{10,11}$

Although alanine and arginine play important roles in the chemistry of proteins, we here examine their reactivity on the $\mathrm{Ge}(100)-2 \times 1$ surface as multifunctional organic molecules (Figure 1). However, these results also serve as a basis for how these individual amino acids would interact with the Ge(100)$2 \times 1$ surface as part of a polypeptide. We have also explored the reactivity of amino acids on the $\mathrm{Si}(100)-2 \times 1$ surface, ${ }^{12}$ although the Ge surface may have several advantages over the Si surface. First, because differences in reaction barriers tend to be larger on $\mathrm{Ge}$ than on $\mathrm{Si}$, it has been proposed that greater

* Corresponding author. E-mail: chasm@stanford.edu.
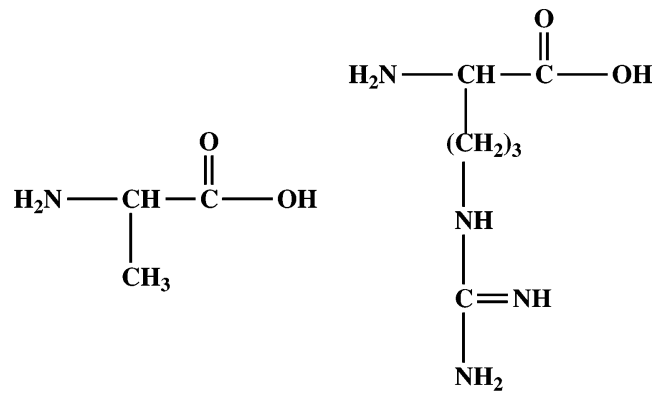

Alanine

Arginine

Figure 1. Schematic view of the amino acids alanine and arginine

reaction selectivity can be achieved. ${ }^{13-15}$ Typically, bonds formed with $\mathrm{Ge}$ are weaker than analogous bonds with Si. Consequently, species that adsorb on the Ge(100)- $2 \times 1$ surface are more likely to reversibly desorb than analogous adsorbates on $\mathrm{Si}(100)-2 \times 1$, thus increasing the thermodynamic selectivity upon heating. On the other hand, many reactions at the $\mathrm{Si}(100)$ surface are under kinetic control and proceed over small activation barriers, which leads to poor selectivity. Moreover, strong bonding of the organic species with the Si(100) surface often results in larger desorption barriers than barriers to decomposition so that adducts primarily irreversibly decompose upon annealing on Si. This could be an important factor for multifunctional systems like amino acids that have many possible reaction routes available to them. Second, Ge can generally be processed at lower temperatures than $\mathrm{Si}$ and consequently if one were to fabricate a hybrid proteinsemiconductor device, lower processing temperatures would be more compatible with preservation of the protein structure. ${ }^{16}$

Direct attachment of polypeptides to semiconductor surfaces using vapor deposition techniques will most likely not be practical. Nevertheless, approaches that involve first functionalizing the surface with an amino acid to form an organic monolayer, and then exposing this film to a solvated biomol- 
ecule, might be capable of producing hybrid biomolecular and semiconductor systems. Here, the amino acid acts as a linking molecule to bind the biomolecule to the substrate and to control the semiconductor-biomolecule interface. Thus, amino acids are excellent candidates to study the selectivity of the reactions of their different functional groups on semiconductor substrates. ${ }^{12,17}$

Our recent theoretical study on the reactivity of amino acids on the $\mathrm{Si}(100)-2 \times 1$ surface has shown that, as expected, many of the reactions of the amino acids on $\mathrm{Si}(100)$ are similar to those of simpler organic molecules when reacting through analogous functional groups. For example, the energetics of the reactions of the common carbonyl, hydroxyl, and amine groups are almost identical to what has been calculated previously on the $\operatorname{Si}(100)-2 \times 1$ surface. ${ }^{14,18}$ However, we also identified several mechanisms that had not been previously investigated, especially for the reactions of arginine and histidine. ${ }^{12} \mathrm{We}$ found that the imine group of arginine's guanidine side chain forms a strong "dative" bond where the imine lone pair acts as a Lewis base and the electrophilic "down" atom of the $\mathrm{Si}(100)-2 \times 1$ surface acts as a Lewis acid. The imine dative bond strength is calculated to be $41.3 \mathrm{kcal} / \mathrm{mol}$, which is stronger than any previously studied dative bond on $\operatorname{Si}(100)-2 \times 1$, including those of amines, nitriles, and ammonia. The strength of this state is attributed to the large proton affinity of the imine nitrogen, consistent with it being a strong Lewis base. The dative bond formed between histidine's cyclic imine nitrogen and the $\operatorname{Si}(100)-2 \times 1$ surface is $30.1 \mathrm{kcal} / \mathrm{mol}$, which is also relatively strong. ${ }^{12} \mathrm{We}$ predicted that the imine dative bonded state undergoes $\mathrm{N}-\mathrm{H}$ dissociation, either by direct means or via a percyclic ene reaction. On the basis of these results, we here investigate the reactions of arginine on the $\mathrm{Ge}(100)-2 \times 1$ surface, including the ene reactions, different possible $\mathrm{N}-\mathrm{H}$ dissociations and $\mathrm{N}=\mathrm{C}[2+2]$ cycloaddition.

Alanine is a simple amino acid that consists of the common group and a methyl side chain. The side chain is unreactive toward the $\mathrm{Si}$ or $\mathrm{Ge}(100)-2 \times 1$ surfaces allowing us to use it as a model to explore the reactivity of the common group toward Ge(100)- $2 \times 1$. Possible reactions include carbonyl and amine dative bonding, $\mathrm{O}-\mathrm{H}$ and $\mathrm{N}-\mathrm{H}$ dissociations, $\mathrm{N}-\mathrm{C}$ dissociation, $\mathrm{H}$ transfer via an ene reaction, and $[2+2]$ cycloaddition. Dupont et al. argued that reaction of the common group with the $\mathrm{Si}(100)-2 \times 1$ surface results in $\mathrm{O}-\mathrm{H}$ dissociation as the major product and $\mathrm{N}-\mathrm{H}$ dissociation as a minor product. ${ }^{12}$ The results presented here indicate that the common group reacts similarly with $\operatorname{Ge}(100)-2 \times 1$, although with higher selectivity.

\section{Computational Details}

The $\mathrm{Ge}_{9} \mathrm{H}_{12}$ one-dimer cluster was used to model the reactivity of the $\mathrm{Ge}(100)-2 \times 1$ surface toward reactions involving only a single dimer. This cluster consists of two Ge atoms representing the surface dimer and seven $\mathrm{Ge}$ atoms modeling three layers of subsurface bulk-like atoms. The dangling bonds of the subsurface atoms are terminated by twelve hydrogen atoms to mimic the $\mathrm{sp}^{3}$ hybridization of bulk Ge. Clusters have been used previously as models of surface reactive sites to predict reaction products on both the Ge and $\mathrm{Si}(100)-2 \times 1$ surfaces and generally produce results consistent with experimental observations except in cases where significant interactions extend beyond the edge of the cluster.7,14,15,18-22

Calculations were performed using density functional theory (DFT) with the Becke3 Lee-Yang-Parr (B3LYP) hybrid and gradient corrected exchange functional. ${ }^{23-25}$ The electronic structure was expanded over atomic Gaussian basis functions using a mixed basis set scheme with the polarized double- $\zeta$ 6-31G(d) basis used for chemically active atoms, the 6-31G basis set used for the chemically inactive atoms of the amino acid, and the LANL2 effective core potential and valence double- $\zeta$ basis set (LANL2DZ) employed for describing the chemically inactive subsurface Ge atoms. This scheme is designed to minimize computational cost while allocating additional basis functions for describing parts of the system that undergo significant modification to the electronic structure during reaction.

Optimizations were obtained without any constraints or symmetry restrictions. Arginine's side chain was modeled as $N$-methylguanidine. In this case, the only chemically inactive atoms of the organic are those of the methyl terminating group, which represents the inert portion of the side chain that we have truncated. We do not employ a truncated model to describe alanine, and the mixed basis set scheme is similar to what was used for arginine; however, in this case, the only chemically active atoms are the atoms of the amine and carboxylic acid groups.

A frequency calculation was performed after each geometry optimization to determine zero-point energies and to verify that minima and transition states have zero and only one imaginary frequency, respectively. Moreover, all of the transition states were visually inspected to ensure that the imaginary modes corresponded to the correct reactions. Single-point energies using a more extensive mixed basis set were performed on the optimized structures and energies from the higher level of theory are reported. For this the triple- $\zeta 6-311++\mathrm{G}(\mathrm{d}, \mathrm{p})$ basis set was employed except for the seven subsurface germanium atoms, which were described using the LANL2DZ effective core potential and basis. This approach has been found to reproduce experiment and the results of high level methods such as quadratic configuration interaction singles and doubles and connected triples (QCISD(T)) relatively accurately. ${ }^{18}$ Energies reported herein are zero-point corrected. All calculations were performed using the Gaussian 03 software package. ${ }^{26}$

\section{Results and Discussion}

3.1. Alanine. Glycine is the simplest amino acid consisting of the carboxylic acid and amine groups of the common group and only a hydrogen atom for a side chain. Alanine is only slightly larger with an inert methyl group as its side chain. Both glycine and alanine have the same reactivity because the $\mathrm{C}-\mathrm{C}$ and $\mathrm{C}-\mathrm{H} \sigma$-bonds of their side chains do not react with $\mathrm{Si}$ or $\mathrm{Ge}(100)-2 \times 1$ surfaces except at high temperatures, and replacement of the $\mathrm{H}$ atom side chain with a methyl side chain has essentially no effect on the common group reactivity. On the other hand, the common group does react with these surfaces and in this study we explored several different possible reactions between alanine and the $\mathrm{Ge}(100)-2 \times 1$ surface. These include $\mathrm{C}=\mathrm{O}$ and $\mathrm{O}-\mathrm{H}$ dative bonding to the electrophilic down $\mathrm{Ge}$ atom of the dimer followed by $\mathrm{O}-\mathrm{H}$ dissociation from each adsorbed state, direct [2+2] cycloaddition and [2+2] cycloaddition proceeding through the $\mathrm{C}=\mathrm{O}$ dative bonded state (Figure 2). We also calculated $\mathrm{N}-\mathrm{H}$ and $\mathrm{N}-\mathrm{C}$ dissociations from the amine dative bonded state (Figure 3).

Figures 2 and 4 illustrate three different adsorbed states; cis and trans $\mathrm{C}=\mathrm{O}$ dative bonded states, where the $\mathrm{H}$ of the hydroxyl group lies cis or trans to the $\mathrm{O}=\mathrm{C}-\mathrm{O}$ plane, and an $\mathrm{O}-\mathrm{H}$ dative bonded state. We calculate that the cis-conformer adsorption energy is $21.7 \mathrm{kcal} / \mathrm{mol}$ whereas the adsorption energy of the trans-conformer is $11.0 \mathrm{kcal} / \mathrm{mol}$. The cisconformer dative bonded state is also more stable than other 
- $\mathrm{O}-\mathrm{H}$ dissociation through $\mathrm{C}=\mathrm{O}$ dative bonding

- - - O-H dissociation through O-H dative bonding

$--\mathrm{C}=\mathrm{O}[2+2]$ cycloaddition
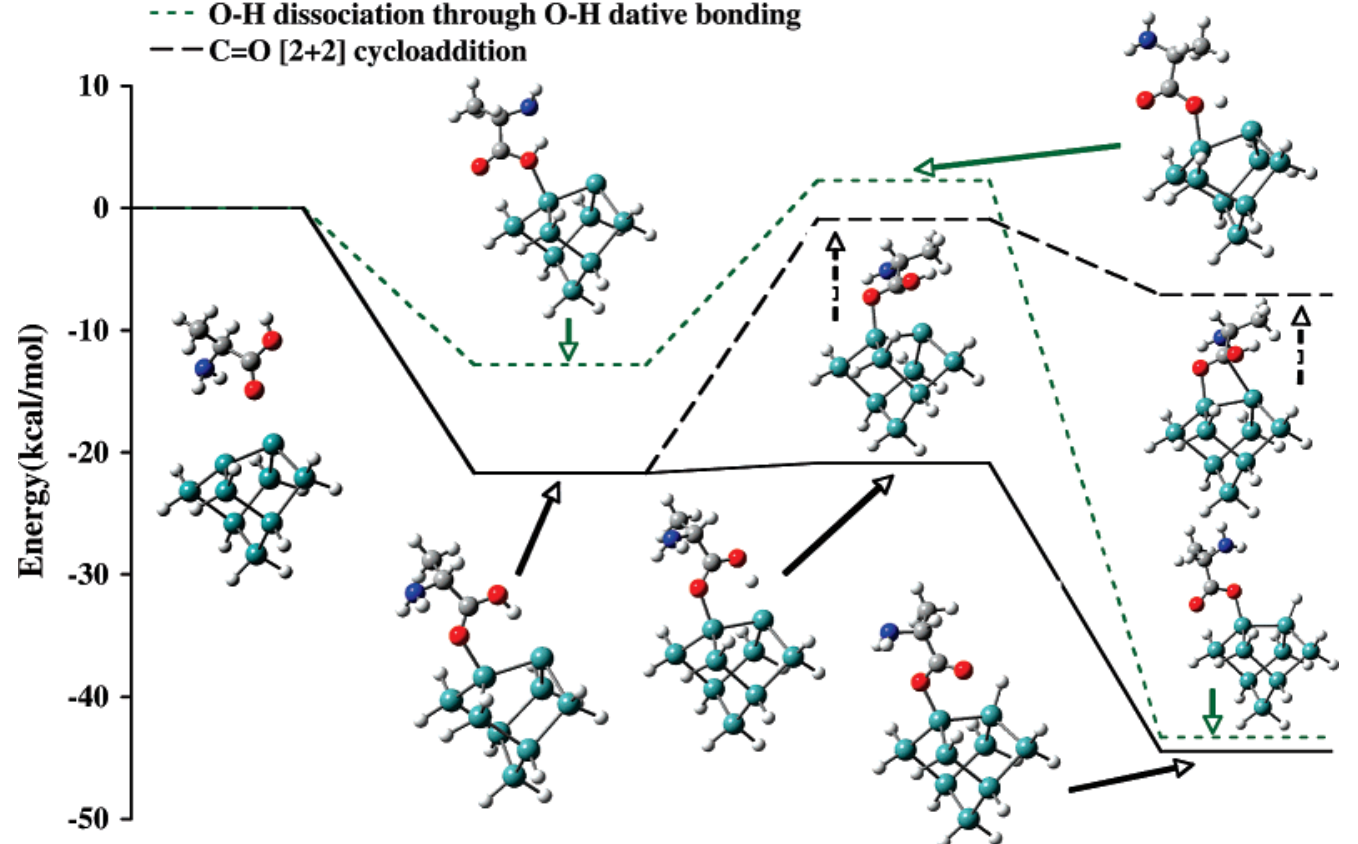

Figure 2. $\mathrm{O}-\mathrm{H}$ dissociation and $\mathrm{C}=\mathrm{O}[2+2]$ cycloaddition reactions of alanine on the $\mathrm{Ge}(100)-2 \times 1$ surface.

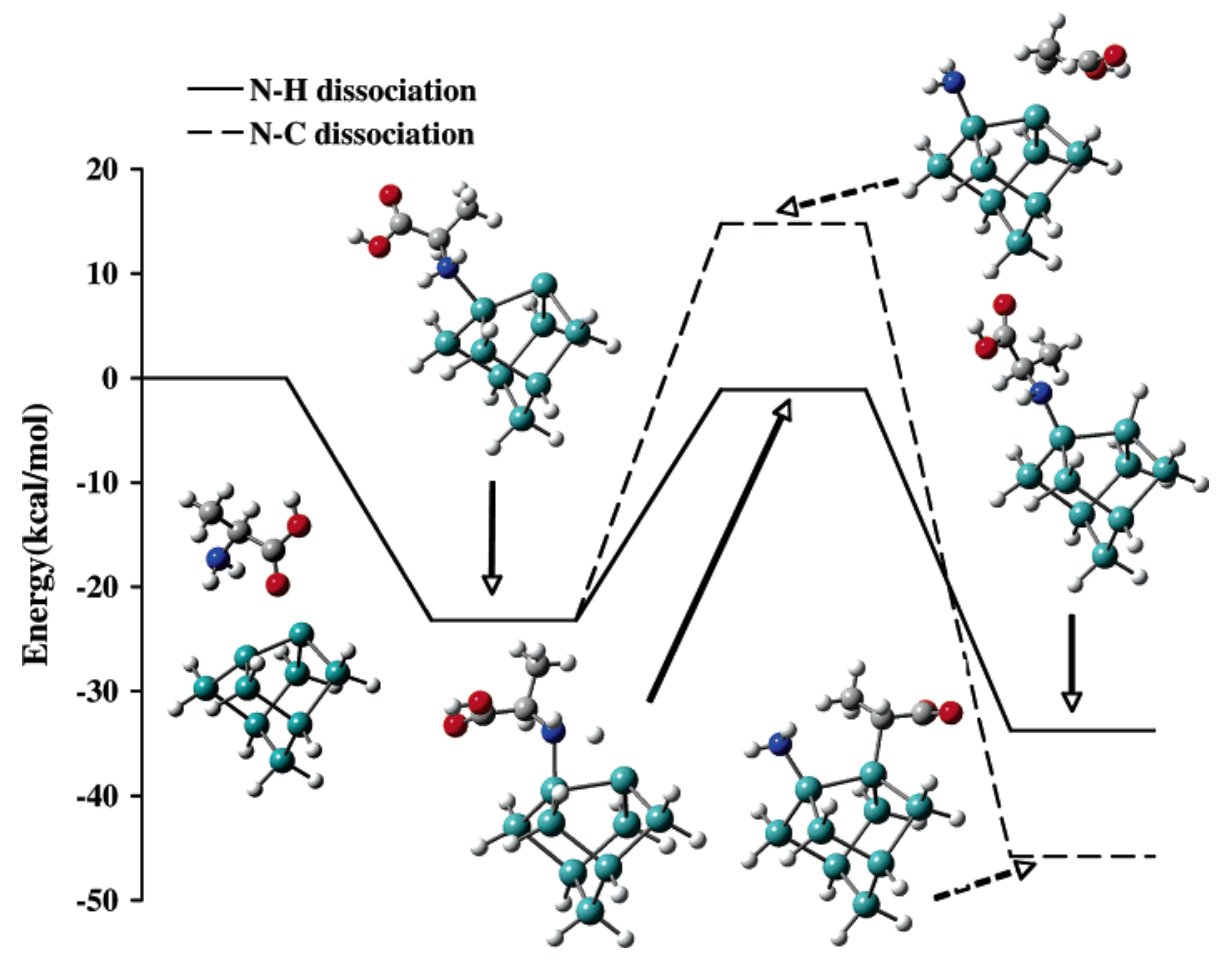

Figure 3. $\mathrm{N}-\mathrm{H}$ and $\mathrm{N}-\mathrm{C}$ dissociation reactions of alanine on the $\mathrm{Ge}(100)-2 \times 1$ surface.

carbonyl dative bonded states on $\mathrm{Ge}(100)-2 \times 1$. Filler et al. reported $\mathrm{C}=\mathrm{O}$ dative bonds with $\mathrm{B} 3 \mathrm{LYP}$ energies of 16.5 and $8.2 \mathrm{kcal} / \mathrm{mol}$ for carboxylic acid and formaldehyde on $\mathrm{Ge}(100)$ $2 \times 1$, respectively. ${ }^{14,20}$ Similarly, Wang et al. used B3LYP to calculate $\mathrm{C}=\mathrm{O}$ dative bonds strengths of 11 and $12 \mathrm{kcal} / \mathrm{mol}$ for ethylvinyl ketone and acetone on $\mathrm{Ge}(100)-2 \times 1 .{ }^{13,15} \mathrm{We}$ attribute the higher calculated stability of the cis-conformer primarily to hydrogen bonding to the nucleophilic surface $\mathrm{Ge}$ atom. This conformational difference might lead to a variety of $\mathrm{O}-\mathrm{H}$ dissociated products. The experimental evidence is exhibited as a doublet carbonyl peak in the IR spectra of acetic acid, acetic- $d_{3}$ acid- $d$ and formic acid saturation exposures on
Ge(100)- $2 \times 1$ at $310 \mathrm{~K} .{ }^{14}$ Here hydrogen bonding between the trans-conformer and a carbonyl group of a neighboring adsorbed alanine is possible, but to investigate this structure, models with multiple dimers are necessary to determine adsorbate-adsorbate interactions, which we leave for further investigation.

From the $\mathrm{C}=\mathrm{O}$ dative bonded cis-conformer adsorbed state possible reaction pathways include $\mathrm{O}-\mathrm{H}$ dissociation via the electrocyclic ene reaction resulting in a product $44.5 \mathrm{kcal} / \mathrm{mol}$ more stable than the initial reactants with a barrier of only 0.8 $\mathrm{kcal} / \mathrm{mol}$. The stability of the product and low reaction barrier make this pathway both kinetically and thermodynamically favorable and thus we expect it to contribute significantly to 

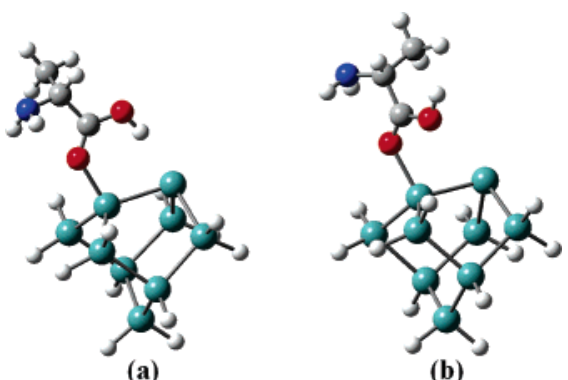

(a)

Figure 4. Alanine carbonyl dative bonded state: (a) cis-conformer and (b) trans-conformer. The cis-conformer is $10.7 \mathrm{kcal} / \mathrm{mol}$ more stable than the trans-conformer.

the product distribution. Alternatively, the [2+2] cycloaddition pathway proceeding from the $\mathrm{C}=\mathrm{O}$ dative bonded state shown in Figure 2 has a barrier of $20.8 \mathrm{kcal} / \mathrm{mol}$ and a product energy $7.1 \mathrm{kcal} / \mathrm{mol}$ below the entrance channel. The relatively large barrier makes this reaction kinetically unfavorable at room temperature. On the other hand, direct $[2+2]$ cycloaddition of alanine is barrierless and exothermic by $7.1 \mathrm{kcal} / \mathrm{mol}$. Although this pathway is thermodynamically less favorable than $\mathrm{O}-\mathrm{H}$ dissociation via the ene reaction from the cis-conformer, we expect it to contribute to the product distribution due to the lack of an enthalpic barrier. In this case the $[2+2]$ cycloaddition product may form transiently before transforming to another stable species or desorbing on a time scale shorter than the experimental technique at room temperature. We found no reaction pathways that proceed directly from the trans dative bonded state as all reactions we investigated initiating from the trans-conformer first convert to the cis-conformer before reacting further.

We also find an alternative pathway that leads to a -43.3 $\mathrm{kcal} / \mathrm{mol} \mathrm{O}-\mathrm{H}$ dissociation product, but proceeding through the $\mathrm{O}-\mathrm{H}$ dative bonded state. As illustrated in Figure 2, the $\mathrm{O}-\mathrm{H}$ dative bonded state lies $12.8 \mathrm{kcal} / \mathrm{mol}$ below the entrance channel with a barrier to $\mathrm{O}-\mathrm{H}$ dissociation of $15.1 \mathrm{kcal} / \mathrm{mol}$ relative to the dative bonded state. Although this pathway leads to an $\mathrm{O}-\mathrm{H}$ dissociation product that is thermodynamically comparable to the ene reaction product, the activation barrier is significantly higher than that of the ene reaction, making this channel relatively inactive at room temperature. However, a fraction of adsorbing molecules may have sufficient energy distributed in the reaction mode before transferring energy to the surface and relaxing into the dative bonded minima in thermal equilibrium with the surface that they surmount the surface at a rate higher than expected from the kinetics of overcoming the reaction barrier from the dative bonded state. Dupont et al. ${ }^{12}$ observe the same reactivity trend on the Si(100)- $2 \times 1$ surface and suggest that the higher barrier for $\mathrm{O}-\mathrm{H}$ dissociation from the $\mathrm{O}-\mathrm{H}$ dative bonded state is due to the strained four-membered ring of the transition state compared to the more conformationally favorable six-membered ring transition state of the ene reaction from the carbonyl dative bonded state.

We calculate an amine dative bonded adsorbed state with a $23.2 \mathrm{kcal} / \mathrm{mol}$ adsorption energy, consistent with the 23.1 and $19.1 \mathrm{kcal} / \mathrm{mol}$ adsorption energies calculated for methylamine and ammonia on $\mathrm{Ge}(100)-2 \times 1$ reported previously. ${ }^{18,22}$ The amine dative bond is slightly stronger than the $21.7 \mathrm{kcal} / \mathrm{mol}$ carbonyl dative bond (Figure 3). Mui et al. also reported adsorption energies for other $\mathrm{Ge}-\mathrm{N}$ dative bonded states including acetonitrile, 2-propenenitrile, and 3-butenenitrile with energies of $11.1,10.4$, and $10.9 \mathrm{kcal} / \mathrm{mol}$, respectively. ${ }^{21} \mathrm{Kim}$ et al. ${ }^{27}$ investigate the reaction of ethylenediamine on $\mathrm{Ge}(100)$ -

TABLE 1: Vibrational Frequencies of the $\mathbf{O}-\mathbf{H}$ Dissociated and Amine and Carbonyl Adsorption Products of Alanine at the $\mathrm{Ge}(100)-2 \times 1$ Surface

\begin{tabular}{|c|c|c|}
\hline product & mode & frequency $\left(\mathrm{cm}^{-1}\right)$ \\
\hline \multirow{11}{*}{$\begin{array}{l}\mathrm{O}-\mathrm{H} \text { dissociation } \\
\text { through } \\
\mathrm{C}-\mathrm{O} \text { dative bond }\end{array}$} & $\mathrm{NH}_{2}$ stretch & 3458,3383 \\
\hline & $\mathrm{CH}_{3}$ stretch & $3004,2994,2919$ \\
\hline & $\mathrm{C}-\mathrm{H}$ stretch & 2975 \\
\hline & $\mathrm{Ge}-\mathrm{H}$ stretch & 2042 \\
\hline & $\mathrm{C}=\mathrm{O}$ stretch & 1670 \\
\hline & $\mathrm{NH}_{2}$ scissors & 1662 \\
\hline & $\mathrm{CH}_{3}$ bend & $1484,1476,1387$ \\
\hline & $\mathrm{C}-\mathrm{H}$ bend & 1297 \\
\hline & $\mathrm{NH}_{2}$ twisting & 1240 \\
\hline & $\begin{array}{l}\text { skeletal stretch } \\
\text { (with strongest } \\
\text { contribution } \\
\text { from } \mathrm{C}-\mathrm{O} \text { ) }\end{array}$ & 1225 \\
\hline & $\mathrm{C}-\mathrm{N}$ stretch & 1108 \\
\hline \multirow{10}{*}{$\begin{array}{l}\mathrm{O}-\mathrm{H} \text { dissociation } \\
\text { through } \\
\mathrm{O}-\mathrm{H} \text { dative bond }\end{array}$} & $\mathrm{NH}_{2}$ stretch & 3461,3382 \\
\hline & $\mathrm{CH}_{3}$ stretch & 2993, 2978, 2907 \\
\hline & $\mathrm{C}-\mathrm{H}$ stretch & 2971 \\
\hline & $\mathrm{Ge}-\mathrm{H}$ stretch & 2029 \\
\hline & $\mathrm{C}=\mathrm{O}$ stretch & 1686 \\
\hline & $\mathrm{NH}_{2}$ scissors & 1640 \\
\hline & $\mathrm{CH}_{3}$ bend & $1483,1477,1381$ \\
\hline & $\mathrm{C}-\mathrm{H}$ bend & 1310 \\
\hline & $\begin{array}{l}\text { skeletal stretch } \\
\text { (with strongest } \\
\text { contribution } \\
\text { from } \mathrm{C}-\mathrm{O} \text { ) }\end{array}$ & 1254 \\
\hline & $\mathrm{C}-\mathrm{N}$ stretch & 1190 \\
\hline \multirow[t]{12}{*}{$\mathrm{N}-\mathrm{H}$ dative bond } & $\mathrm{O}-\mathrm{H}$ stretch & 3604 \\
\hline & $\mathrm{NH}_{2}$ stretch & 3424,3361 \\
\hline & $\mathrm{CH}_{3}$ stretch & $3030,2996,2921$ \\
\hline & $\mathrm{C}-\mathrm{H}$ stretch & 2952 \\
\hline & $\mathrm{C}=\mathrm{O}$ stretch & 1777 \\
\hline & $\mathrm{NH}_{2}$ scissors & 1636 \\
\hline & $\mathrm{CH}_{3}$ bend & $1484,1483,1407$ \\
\hline & $\mathrm{C}-\mathrm{H}$ bend & 1334 \\
\hline & $\mathrm{O}-\mathrm{H}$ bend & 1294 \\
\hline & $\mathrm{NH}_{2}$ twisting & 1239 \\
\hline & $\mathrm{NH}_{2}$ wagging & 1162 \\
\hline & $\mathrm{C}-\mathrm{O}$ stretch & 1119 \\
\hline \multirow[t]{10}{*}{$\mathrm{C}=\mathrm{O}$ dative bond } & $\mathrm{NH}_{2}$ stretch & 3469,3394 \\
\hline & $\mathrm{CH}_{3}$ stretch & $3019,2999,2924$ \\
\hline & $\mathrm{C}-\mathrm{H}$ stretch & 2973 \\
\hline & $\mathrm{O}-\mathrm{H}$ stretch & 2780 \\
\hline & $\mathrm{NH}_{2}$ scissors & 1664 \\
\hline & $\mathrm{C}=\mathrm{O}$ stretch & 1570 \\
\hline & $\mathrm{CH}_{3}$ bend & $1484,1479,1406,1382$ \\
\hline & $\mathrm{C}-\mathrm{H}$ bend & 1277 \\
\hline & $\mathrm{NH}_{2}$ twisting & 1246 \\
\hline & $\mathrm{O}-\mathrm{H}$ bend & 1204 \\
\hline
\end{tabular}

$2 \times 1$ and report the formation of a single intradimer $\mathrm{Ge}-\mathrm{N}$ dative bonded state $27.0 \mathrm{kcal} / \mathrm{mol}$ below the entrance channel. The differences in dative bonded adsorption energies is mostly a function of the nature of the $\mathrm{N}$ lone pair, additional interactions with the surface such as hydrogen bonding or formation of a second dative bond, and the effects of the neighboring carboxylic acid. However, for analogous interactions, some of the differences between the present work and the literature are due to differences in the methods, basis sets and surface models employed.

From the amine dative bonded adsorbed state we investigated two reaction pathways. One is $\mathrm{N}-\mathrm{C}$ dissociation, which we calculate to be exothermic by $45.8 \mathrm{kcal} / \mathrm{mol}$, although it proceeds over a $37.9 \mathrm{kcal} / \mathrm{mol}$ barrier making it kinetically unfavorable at room temperature. The second is $\mathrm{N}-\mathrm{H}$ dissociation, with a calculated transition state energy $1.1 \mathrm{kcal} / \mathrm{mol}$ below the entrance channel and thus an activation barrier of $22.1 \mathrm{kcal} / \mathrm{mol}$. This reaction is exothermic by $33.7 \mathrm{kcal} / \mathrm{mol}$, in agreement with 

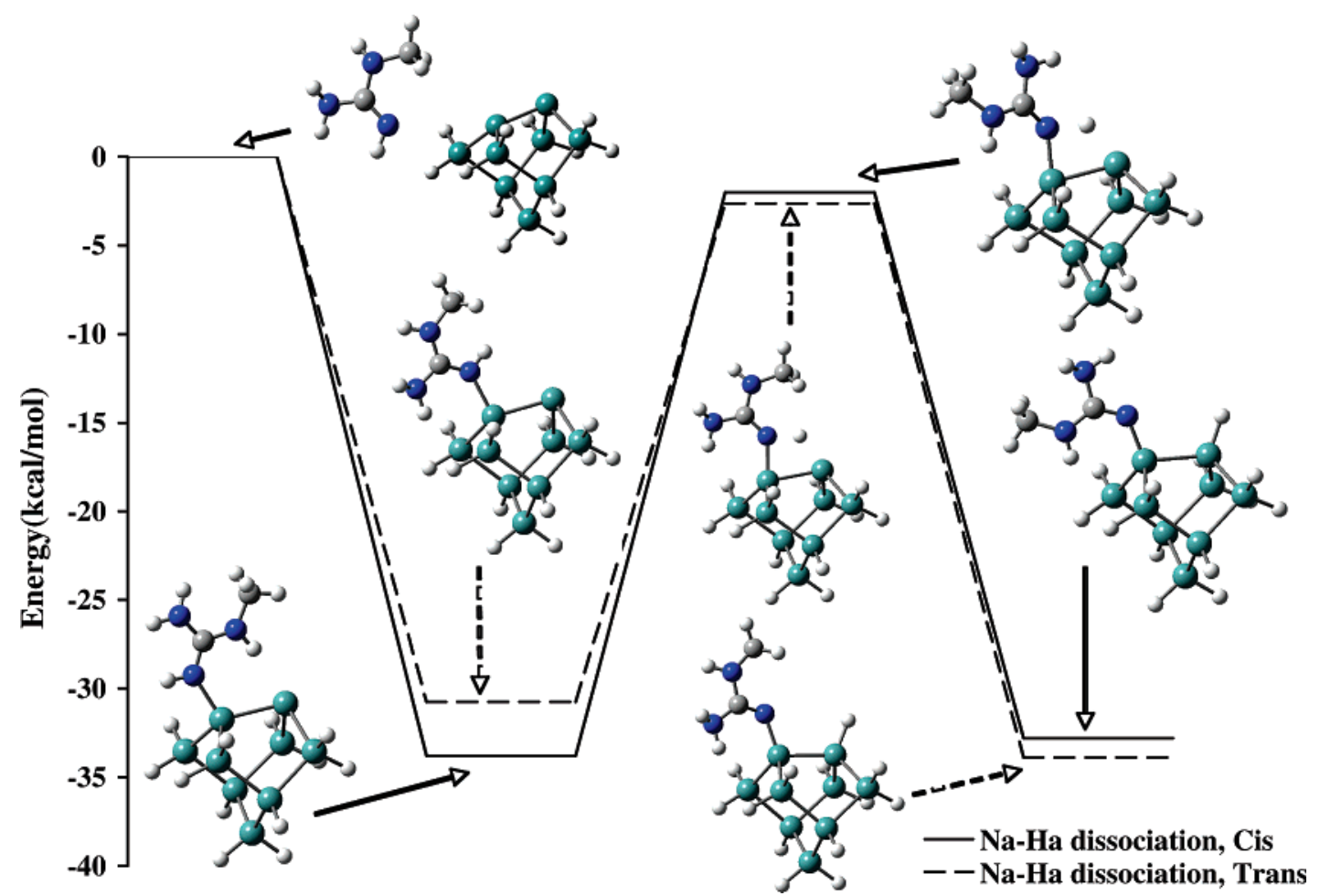

Figure 5. Reactions of the $N$-methylguanidine model of arginine on the Ge(100)-2 $\times 1$ surface; $\mathrm{N}_{\mathrm{a}}-\mathrm{H}_{\mathrm{a}}$ dissociation for the cis and trans imine dative bonded conformers.

previous work. ${ }^{18}$ The relatively high barrier to $\mathrm{N}-\mathrm{H}$ dissociation suggests that this reaction will not contribute significantly to the product distribution, except at high temperatures. However, because adsorption to form the amine dative bond is barrierless and $\mathrm{N}-\mathrm{H}$ dissociation lies below the entrance channel, it is kinetically and thermodynamically favorable for adsorbing molecules to form the amine dative bonded state from which it is equally kinetically favorable to undergo $\mathrm{N}-\mathrm{H}$ dissociation (22.1 kcal $/ \mathrm{mol}$ barrier) or to desorb $(23.2 \mathrm{kcal} / \mathrm{mol} \mathrm{barrier})$. Furthermore, depending on the dynamics of energy transfer it is also possible that $\mathrm{N}-\mathrm{H}$ dissociation may occur without proceeding through the amine dative bonded state. Consequently, the product distributions can be affected by the dynamics of adsorption and not be under either strict thermodynamic or kinetic control. However, with this caveat our results predict that the ene reaction $\mathrm{O}-\mathrm{H}$ dissociation pathway from the carbonyl dative bonded cis-conformer is both thermodynamically and kinetically favorable and the $\mathrm{O}-\mathrm{H}$ dissociated product through this pathway is expected to be the majority product on the $\mathrm{Ge}(100)-2 \times 1$ surface with the amine adsorbed state being a minority product. Table 1 shows the vibrational modes for the $\mathrm{O}-\mathrm{H}$ dissociated, carbonyl and amine adsorbed products scaled by 0.9679 and computed using B3LYP with $6-311 \mathrm{G}$ describing the chemically inactive atoms, $6-311+\mathrm{G}(\mathrm{d})$ describing alanine and Ge dimer atoms and LANL2DZ describing subsurface $\mathrm{Ge}$ atoms. ${ }^{28}$

3.2. Arginine. Dupont et al. argued that the reactions of the arginine common group on the $\mathrm{Si}(100)-2 \times 1$ surface should be similar to those of glycine and alanine. ${ }^{12}$ Likewise, we expect that common group reactions of arginine on the $\mathrm{Ge}(100)-2 \times 1$ surface are similar to those of alanine and thus we only explore reactions involving arginine's guanidine side chain. The potential energy profiles for these reactions are illustrated in Figures 5-7. To reduce the complexity of the computations, we model the side chain as $N$-methylguanidine. As shown in Figure 8, arginine's side chain has two amine nitrogens (labeled b and c) and one imine nitrogen (labeled a). Hence, three $\mathrm{N}$ dative bonded adsorbed states and various reaction pathways are possible for this system.

We found two comformationally different imine adsorbed states (Figure 9) where the imine $\mathrm{N}$ acts as a Lewis base and dative bonds to the electrophilic down atom of the dimer, which acts as a Lewis acid. The imine $\mathrm{C}=\mathrm{N}$ bond lies cis or trans to the surface dimer and from each of these conformations $\mathrm{N}-\mathrm{H}$ dissociation can occur either by direct means from the imine $\mathrm{N}$ or through an ene reaction. Figures 5 and 6 show reaction pathways for both of these reactions where the hydrogen transferred to the surface in each conformation is oriented toward the dangling bond of the surface dimer. The trans- and cisconformers have adsorption energies of 30.7 and $33.8 \mathrm{kcal} / \mathrm{mol}$, respectively. The energy difference may be attributed to H-bonding between $\mathrm{H}_{\mathrm{b}}$, the $\mathrm{H}$ atom bonded to $\mathrm{N}_{\mathrm{b}}$, and the nucleophilic up Ge dimer atom. In both cases, the imine dative bonds are significantly stronger than other $\mathrm{Ge}-\mathrm{N}$ dative bonds reported previously for amines, nitriles, and ammonia on Ge(100)- $2 \times 1 .^{18,21,22}$ Dupont et al. ${ }^{12}$ observe the same trend on Si(100)- $2 \times 1$ where they found a $41.3 \mathrm{kcal} / \mathrm{mol}$ adsorption energy on the one-dimer cluster. As expected and shown previously, the adsorbed states are less stable on the (100)- $2 \times 1$ surface of $\mathrm{Ge}$ than on $\mathrm{Si}^{2,15,18,19} \mathrm{We}$ have previously calculated that amine reaction energetics on $\mathrm{Si}$ and $\mathrm{Ge}$ are sensitive to the size of the cluster model of the surface..$^{22,29,30}$ To determine whether this effect is exhibited in the imine ene reaction of arginine on $\mathrm{Ge}$, we also calculate the reaction energetics using a three-dimer cluster. The adsorption energy for the cis-conformer on the three-dimer cluster with the dimers lying in the same row is $33.0 \mathrm{kcal} / \mathrm{mol}$, within $1 \mathrm{kcal} / \mathrm{mol}$ of the one-dimer result. This is consistent with the results of Mui et al. ${ }^{22}$ for ammonia dative bonds on $\mathrm{Ge}(100)-2 \times 1$, which are relatively insensitive to the cluster size effect. Dupont et al. ${ }^{12}$ calculate gas-phase proton affinities to show that the imine $\mathrm{N}$ of $\mathrm{N}$-methylguanidine is a stronger Lewis base than the amine $\mathrm{N}$ of $\mathrm{N}$-methylguanidine 


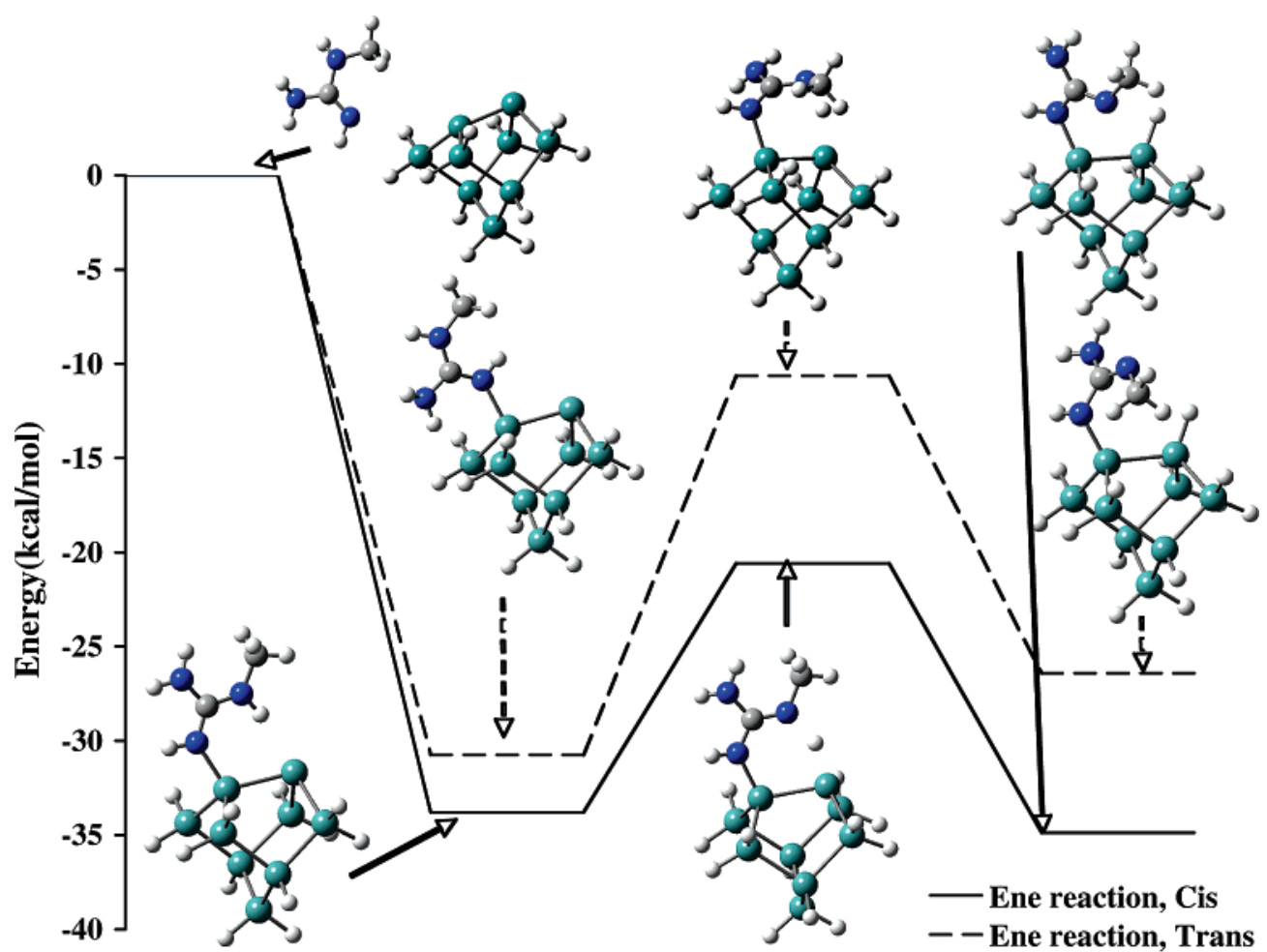

Figure 6. Reactions of the $N$-methylguanidine model of arginine on the Ge(100)- $2 \times 1$ surface; ene reaction for the cis and trans imine dative bonded conformers.

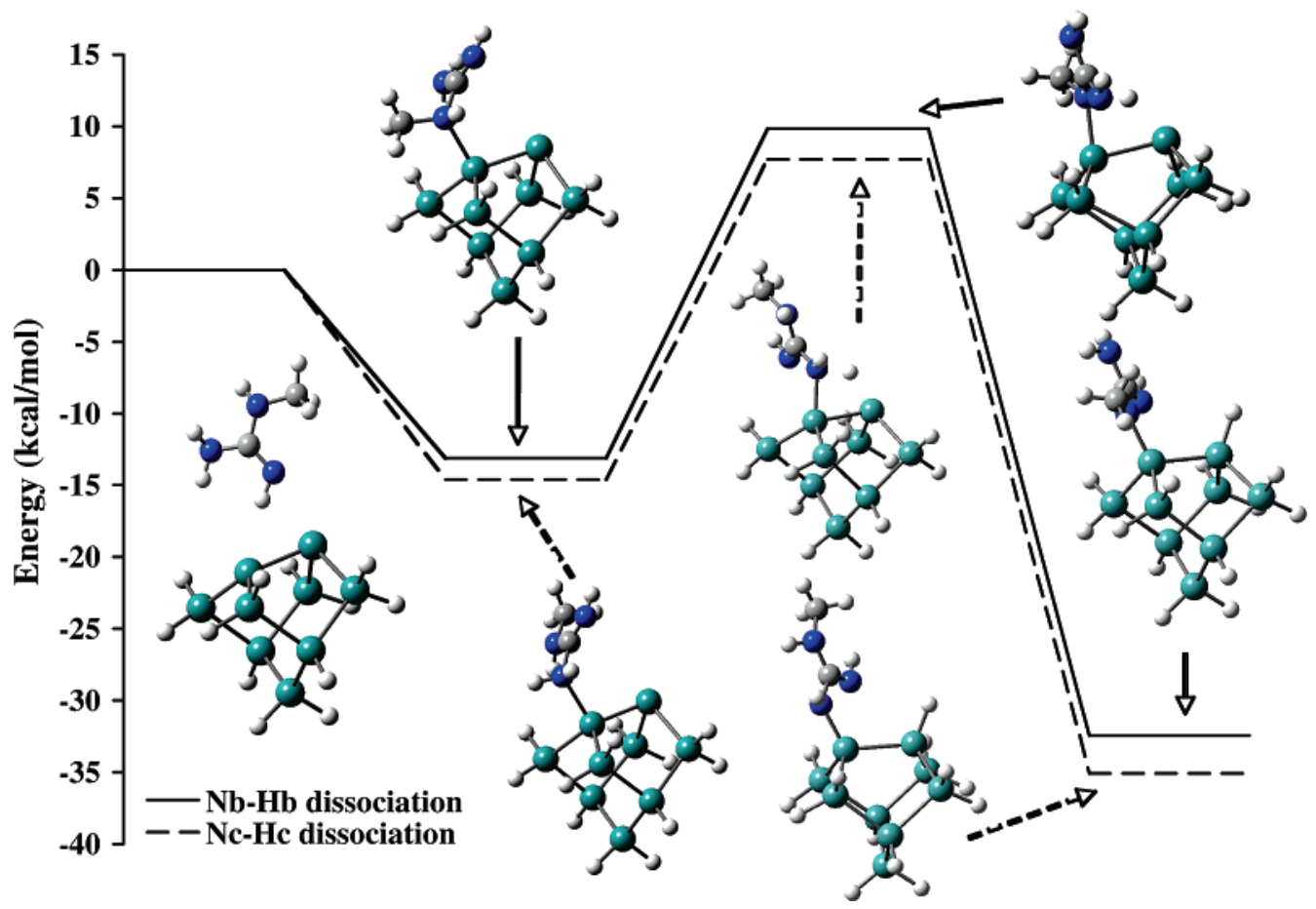

Figure 7. Reactions of the $N$-methylguanidine model of arginine on the Ge(100)-2×1 surface; $\mathrm{N}_{\mathrm{b}}-\mathrm{H}_{\mathrm{b}}$ and $\mathrm{N}_{\mathrm{c}}-\mathrm{H}_{\mathrm{c}}$ dissociations.

and methylamines. Consequently, they suggest the delocalization of the positive charge on the imine nitrogen to the neighboring amine nitrogens as the origin of the stability of this adsorbed state. We show the calculated $\mathrm{C}-\mathrm{N}$ and $\mathrm{Ge}-\mathrm{N}$ bond lengths for the adsorbed states and reactants in Table 2. The imine $\mathrm{Ge}-\mathrm{N}$ dative bond length is intermediate between amine-like $\mathrm{Ge}-\mathrm{N}$ dative bonds $(2.13-2.18 \AA)$ and a $\mathrm{Ge}-\mathrm{N}$ covalent bond $(1.7 \AA) .{ }^{18}$ The $\mathrm{C}-\mathrm{N}_{\mathrm{a}}, \mathrm{C}-\mathrm{N}_{\mathrm{b}}$, and $\mathrm{C}-\mathrm{N}_{\mathrm{c}}$ bond lengths lie between the $\mathrm{C}=\mathrm{N}$ double bond length $(1.28 \AA)$ and the $\mathrm{C}-\mathrm{N}$ single bond length $(1.4 \AA)$ for both conformers. ${ }^{12}$ The equivalent

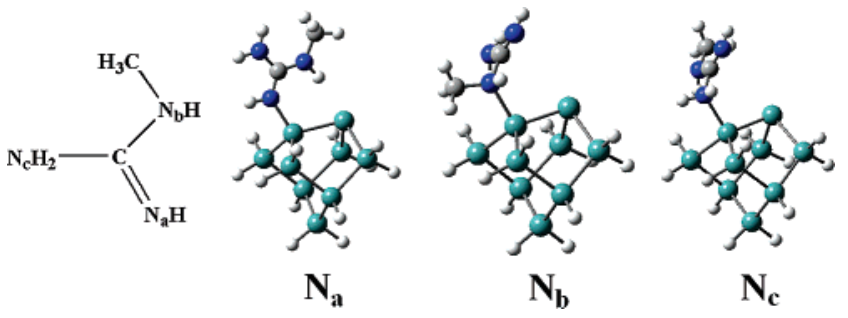

Figure 8. Possible dative bonded adducts of the $N$-methylguanidine model of arginine on the $\mathrm{Ge}(100)-2 \times 1$ surface. 

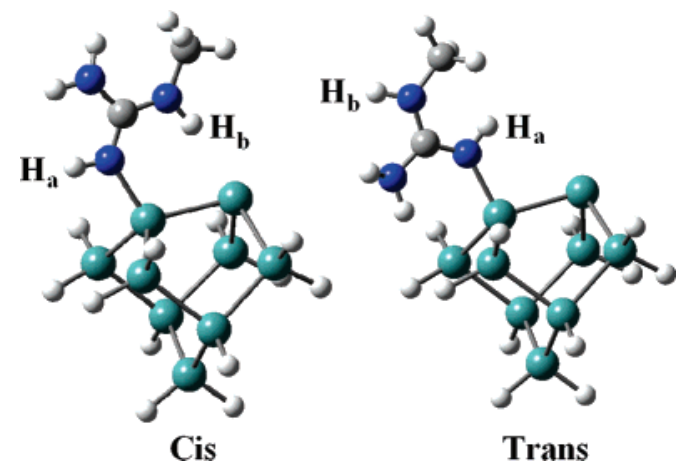

Figure 9. Cis- and trans-conformers of $N$-methylguanidine adsorbed on $\mathrm{Ge}(100)-2 \times 1$.

TABLE 2: Selected Bond Lengths in Angstroms for $N$-Methylguanidine Adsorbed on the $\mathrm{Ge}(100)-2 \times 1$ Surface

\begin{tabular}{ccccc}
\hline conformer & $\mathrm{Ge}-\mathrm{N}_{\mathrm{a}}$ & $\mathrm{C}-\mathrm{N}_{\mathrm{a}}$ & $\mathrm{C}-\mathrm{N}_{\mathrm{b}}$ & $\mathrm{C}-\mathrm{N}_{\mathrm{c}}$ \\
\hline trans & 2.01 & 1.31 & 1.36 & 1.36 \\
cis & 2.00 & 1.32 & 1.34 & 1.37
\end{tabular}

$\mathrm{C}-\mathrm{N}$ bond lengths of the dative bonded state indicate the stabilization gained by the delocalization of the positive charge as described by the resonance model shown in Figure 10. Figure 9 indicates that $\mathrm{a} \mathrm{H}$-bond forms between $\mathrm{H}_{\mathrm{b}}$ and the up $\mathrm{Ge}$ dimer atom in the cis conformation, accounting for the additional 2.9 $\mathrm{kcal} / \mathrm{mol}$ stability of the cis-conformer over the trans-conformer.

We found two distinct dissociation pathways for each of the two imine dative bonded conformers. $\mathrm{N}_{\mathrm{a}}-\mathrm{H}_{\mathrm{a}}$ dissociation proceeds over barriers of 28.1 and $31.7 \mathrm{kcal} / \mathrm{mol}$ for the transand cis-conformers, respectively, with corresponding final product energies of -33.9 and $-32.8 \mathrm{kcal} / \mathrm{mol}$ (Figure 5). Although the $\mathrm{N}_{\mathrm{a}}-\mathrm{H}_{\mathrm{a}}$ dissociation pathways are thermodynamically favored, they require relatively large activation energies. Another possible pathway from the imine dative bonded state results in $\mathrm{N}_{\mathrm{b}}-\mathrm{H}_{\mathrm{b}}$ dissociation through an ene reaction (Figure 6). This reaction involves barriers of 20.1 and $13.2 \mathrm{kcal} / \mathrm{mol}$ for the trans- and cis-conformers with corresponding products energies of -26.4 and $-34.9 \mathrm{kcal} / \mathrm{mol}$. Moreover, we calculate that when using the three-dimer model the ene reaction of the cis-conformer proceeds over an $18.3 \mathrm{kcal} / \mathrm{mol}$ barrier and results in a product energy of $-26.8 \mathrm{kcal} / \mathrm{mol}$. Consequently, although the imine dative bond adsorption energy is unaffected by extending the cluster model, the ene reaction barrier and product energies do change significantly. This energy increase for the ene reaction transition state and product can be attributed to the strain between the middle unbuckled Ge surface dimer and the neighboring buckled Ge surface dimers in the dimer row of the three-dimer model, which is neglected in the one-dimer model and not present in the dative bonded state because the central dimer remains buckled. These results predict that the dative bonded imine state is both thermodynamically and kinetically stable with respect to dissociation via the ene reaction. Relative to the $\mathrm{N}_{\mathrm{a}}-\mathrm{H}_{\mathrm{a}}$ dissociation pathway, the ene
TABLE 3: Vibrational Frequencies Computed for the Arginine's Imine N Dative Bonded States and Ene Reaction Product of the Cis Imine Dative Bonded Conformer at the Ge(100)-2 $\times 1$ Surface

\begin{tabular}{cll}
\hline \multicolumn{1}{c}{ product } & \multicolumn{1}{c}{ mode } & frequency $\left(\mathrm{cm}^{-1}\right)$ \\
\hline imine $\mathrm{N}$ dative bond, & $\mathrm{N}_{\mathrm{c}} \mathrm{H}_{\mathrm{c} 2}$ stretch & 3591,3490 \\
cis-conformer & $\mathrm{N}_{\mathrm{a}} \mathrm{H}_{\mathrm{a}}$ stretch & 3466 \\
& $\mathrm{~N}_{\mathrm{b}} \mathrm{H}_{\mathrm{b}}$ stretch & 3169 \\
& $\mathrm{~N}_{\mathrm{c}} \mathrm{H}_{\mathrm{c} 2}$ scissors & 1653 \\
$\mathrm{C}-\mathrm{N}_{\mathrm{b}}$ & 1626 \\
& $\mathrm{C}-\mathrm{N}_{\mathrm{c}}$ & 1533 \\
& $\mathrm{~N}_{\mathrm{b}} \mathrm{H}_{\mathrm{b}}$ bend & 1434 \\
& $\mathrm{~N}_{\mathrm{a}} \mathrm{H}_{\mathrm{a}}$ bend & 1262 \\
& $\mathrm{~N}_{\mathrm{c}} \mathrm{H}_{\mathrm{c} 2}$ rocking & 1073 \\
& $\mathrm{~N}_{\mathrm{c}} \mathrm{H}_{\mathrm{c} 2}$ stretch & 3564,3452 \\
& $\mathrm{~N}_{\mathrm{b}} \mathrm{H}_{\mathrm{b}}$ stretch & 3513 \\
imine $\mathrm{N}$ dative bond, & $\mathrm{N}_{\mathrm{a}} \mathrm{H}_{\mathrm{a}}$ stretch & 3458 \\
trans-conformer & $\mathrm{N}_{\mathrm{c}} \mathrm{H}_{\mathrm{c} 2}$ scissors & 1645 \\
& $\mathrm{C}-\mathrm{N}_{\mathrm{a}}$ & 1584 \\
& $\mathrm{C}-\mathrm{N}_{\mathrm{b}}$ & 1563 \\
& $\mathrm{~N}_{\mathrm{b}} \mathrm{H}_{\mathrm{b}}$ bend & 1393 \\
& $\mathrm{~N}_{\mathrm{a}} \mathrm{H}_{\mathrm{a}}$ bend & 1252 \\
& $\mathrm{~N}_{\mathrm{c}} \mathrm{H}_{\mathrm{c} 2}$ rocking & 1067 \\
$\mathrm{~N}_{\mathrm{c}} \mathrm{H}_{\mathrm{c} 2}$ stretch & 3551,3456 \\
& $\mathrm{~N}_{\mathrm{a}} \mathrm{H}_{\mathrm{a}}$ stretch & 3470 \\
ene reaction for cis imine & $\mathrm{Ge}^{-}-\mathrm{H}$ stretch & 2033 \\
dative bonded conformer & $\mathrm{C}-\mathrm{N}_{\mathrm{b}}$ & 1659 \\
& $\mathrm{~N}_{\mathrm{c}} \mathrm{H}_{\mathrm{c} 2}$ scissors & 1624 \\
& $\mathrm{C}-\mathrm{N}_{\mathrm{a}}$ & 1387 \\
& $\mathrm{~N}_{\mathrm{a}} \mathrm{H}_{\mathrm{a}}$ bend & 1263 \\
& $\mathrm{~N}_{\mathrm{c}} \mathrm{H}_{\mathrm{c} 2}$ rocking & 1041 \\
& &
\end{tabular}

reaction has considerably lower reaction barriers. Furthermore, the barrier to $\mathrm{N}-\mathrm{H}$ dissociation through the ene reaction is lower for the cis-conformer, whereas $\mathrm{N}_{\mathrm{a}}-\mathrm{H}_{\mathrm{a}}$ dissociation requires a lower activation energy for the trans-conformer because of the relative positions of the dissociating $\mathrm{H}$ atom in the two conformers. At low temperatures it is expected that the barriers for both $\mathrm{N}-\mathrm{H}$ dissociation pathways are sufficiently high that a large fraction of adsorbed arginine will be trapped in the imine dative bonded state. Furthermore, as our three-dimer results predict, $\mathrm{N}-\mathrm{H}$ dissociation of the cis-conformer via the ene reaction is endothermic relative to the imine dative bonded state. Table 3 shows the vibrational modes of the imine $\mathrm{N}$ dative bonded states and ene reaction product of the cis imine dative bonded conformer scaled by 0.9679 and computed using B3LYP with 6-311G describing the chemically inactive atoms, 6-311+G(d) describing $\mathrm{N}$-methylguanidine and $\mathrm{Ge}$ dimer atoms and LANL2DZ describing the subsurface Ge atoms of the $\mathrm{Ge}_{9} \mathrm{H}_{12}$ one-dimer cluster model. ${ }^{28}$

$N$-Methylguanidine can also adsorb to the $\mathrm{Ge}(100)-2 \times 1$ surface by dative bonding through each of its amine nitrogens(Figure 7). The adsorption energies for the $\mathrm{N}_{\mathrm{b}}$ and $\mathrm{N}_{\mathrm{c}}$ dative bonded states are 13.1 and $14.6 \mathrm{kcal} / \mathrm{mol}$. These adsorbed states are less stable than those reported for the amine systems ${ }^{18}$ due to the effect of the neighboring imine group. The transition states for $\mathrm{N}_{\mathrm{b}}-\mathrm{H}_{\mathrm{b}}$ and $\mathrm{N}_{\mathrm{c}}-\mathrm{H}_{\mathrm{c}}$ dissociation lie 9.8 and $7.7 \mathrm{kcal} / \mathrm{mol}$ above the entrance channel, making the barriers 22.9 and 22.3

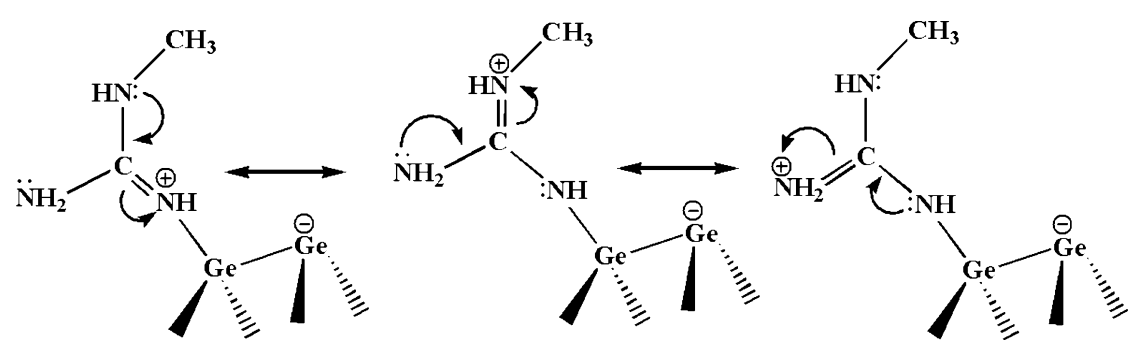

Figure 10. Resonance model representing the dative bonding of $N$-methylguanidine to the $\mathrm{Ge}(100)-2 \times 1$ surface via its imine nitrogen atom. 
$\mathrm{kcal} / \mathrm{mol}$ from their respective dative bonded states. We calculate product energies for $\mathrm{N}_{\mathrm{b}}-\mathrm{H}_{\mathrm{b}}$ and $\mathrm{N}_{\mathrm{c}}-\mathrm{H}_{\mathrm{c}}$ dissociation of -32.4 and $-35.1 \mathrm{kcal} / \mathrm{mol}$, and although the reactions are exothermic, their relatively high activation barriers and less stable product energies suggest that these reactions will not contribute significantly to the product distribution, except possibly at moderately high temperatures.

We have also calculated the $\mathrm{N}=\mathrm{C}[2+2]$ cycloaddition product and found its energy to be only $3.3 \mathrm{kcal} / \mathrm{mol}$ below the energy of the reactants. However, Mui et al. ${ }^{21}$ report a reaction energy of $-8.4 \mathrm{kcal} / \mathrm{mol}$ for [2+2] cycloaddition of nitriles on $\mathrm{Ge}(100)-2 \times 1$. Here the divergence is caused by differences between the imine and nitrile $\mathrm{C}-\mathrm{N} \pi$-bonds. This is a minor distinction as its low stability results in a short lifetime such that we do not expect to observe this product on the Ge(100)$2 \times 1$ surface.

\section{Conclusions}

We have used DFT and mixed basis sets to investigate the reactions of alanine and arginine on the $\mathrm{Ge}(100)-2 \times 1$ surface using a single-dimer cluster model and have found a number of reaction pathways and various stable adsorbed species. Our calculations for alanine reveal that $\mathrm{O}-\mathrm{H}$ dissociation from the carbonyl dative bonded state likely produces the majority product on the surface because it is both kinetically and thermodynamically favorable. We predict an adsorption energy for a state dative bonded through the amine functional group slightly larger than that of the carbonyl dative bonded state. Hence, we expect this product will also be observed. Arginine exhibits unique reactivity on $\mathrm{Ge}(100)-2 \times 1$. We find that the adsorbed states that result from the imine nitrogen dative bonding to the surface are the most stable products on $\mathrm{Ge}(100)$ $2 \times 1$. This can be attributed to the extensive delocalization of the imine $\mathrm{N}$ positive charge over the amine nitrogens upon formation of the $\mathrm{Ge}$-imine $\mathrm{N}$ dative bond. We have shown that the reaction barriers and product stabilities are consistent with the orientation of $\mathrm{H}$ atoms with respect to the $\mathrm{Ge}$ dimer in the trans and cis imine dative bonded conformers. The reaction profile of the three-dimer cluster predicts that the imine dative bonded state is stable against decomposition via the ene reaction as this barrier is $18.3 \mathrm{kcal} / \mathrm{mol}$ and the reaction is $6.2 \mathrm{kcal} / \mathrm{mol}$ endothermic with respect to the dative bonded state. The interactions of the amine nitrogens of $\mathrm{N}$-methylguanidine with the $\mathrm{Ge}(100)-2 \times 1$ surface show that their corresponding pathways will not contribute to the final product except at high temperatures. Both imine dative bonded states are significantly more stable than any other dative bonds to $\mathrm{Ge}(100)-2 \times 1$ yet reported. Consequently, arginine can be used to strongly couple organic species to Ge based semiconductors, which might be useful for making biological sensors.

Acknowledgment. We gratefully acknowledge the support of the Stanford Initiative for Nanoscale Materials and Processing and useful discussions with Dr. Ankan Paul. N.D. thankfully acknowledges financial support from Prof. N. A. Melosh.

\section{References and Notes}

(1) Bent, S. F. Surf. Sci. 2002, 500, 879.

(2) Filler, M. A.; Bent, S. F. Prog. Surf. Sci. 2003, 73, 1

(3) Lin, Z.; Strother, T.; Cai, W.; Cao, X. P.; Smith, L. M.; Hamers, R. J. Langmuir 2002, 18, 788.

(4) Lu, X.; Lin, M. C. Int. Rev. Chem. 2002, 21, 137.

(5) Hamers, R. J.; Hovis, J. S.; Lee, S.; Liu, H. B.; Shan, J. J. Phys. Chem. B 1997, 101, 1489 .

(6) Duke, C. B. Chem. Rev. 1996, 96, 1237.

(7) Zandvliet, H. J. W. Phys. Rep. 2003, 388, 1.

(8) Krüger, P.; Pollmann, J. Phys. Rev. Lett. 1995, 74, 1155.

(9) Kubby, J. A.; Griffith, J. E.; Becker, R. S.; Vickers, J. S. Phys. Rev. B 1987, 36, 6079 . 2457.

(11) Schwartz, M. P.; Ellison, M. D.; Coulter, S. K.; Hovis, J. S.; Hamers, R. J. J. Am. Chem. Soc. 2000, 122, 8529.

(12) Dupont, G.; Ardalan, P.; Musgrave, C. B. To be submitted

(13) Wang, G. T.; Mui, C.; Musgrave, C. B.; Bent, S. F. J. Phys. Chem. $B$ 2001, 105, 12559.

(14) Filler, M. A.; Van Deventer, J. A.; Keung, A. J.; Bent, S. F. J. Am. Chem. Soc. 2006, 128,770 .

(15) Wang, G. T.; Mui, C.; Musgrave, C. B.; Bent, S. F. J. Am. Chem. Soc. 2002, 124, 8990 .

(16) Loscutoff, P. W.; Bent, S. F. Annu. Rev. Phys. Chem. 2006, 57, 467.

(17) Lopez, A.; Heller, T.; Bitzer, T.; Richardson, N. Chem. Phys. 2002, $277,1$.

(18) Mui, C.; Han, J. H.; Wang, G. T.; Musgrave, C. B.; Bent, S. F. J. Am. Chem. Soc. 2002, 124, 4027.

(19) Wang, G. T.; Mui, C.; Tannaci, J. F.; Filler, M. A.; Musgrave, C. B.; Bent, S. F. J. Phys. Chem. B 2003, 107, 4982.

(20) Filler, M. A.; Musgrave, C. B.; Bent, S. F. J. Phys. Chem. B, in press

(21) Mui, C.; Filler, M. A.; Bent, S. F.; Musgrave, C. B. J. Phys. Chem. B 2003, 107, 12256.

(22) Mui, C.; Musgrave, C. B. Langmuir 2005, 21, 5230.

(23) Hohenberg, H.; Kohn, W. Phys. Rev. B 1964, 1, 36B864.

(24) Becke, A. D. Phys. Rev. A 1988, 38, 3098.

(25) Lee, C. T.; Yang, W. T.; Parr, R. G. Phys. Rev. B 1988, 37, 785 .

(26) Frisch, M. J.; Trucks, G. W.; Schlegel, H. B.; Scuseria, G. E.; Robb M. A.; Cheeseman, J. R.; Montgomery, J. A., Jr.; Vreven, T.; Kudin, K. N.; Burant, J. C.; Millam, J. M.; Iyengar, S. S.; Tomasi, J.; Barone, V.; Mennucci, B.; Cossi, M.; Scalmani, G.; Rega, N.; Petersson, G. A.; Nakatsuji, H.; Hada, M.; Ehara, M.; Toyota, K.; Fukuda, R.; Hasegawa, J.; Ishida, M.; Nakajima, T.; Honda, Y.; Kitao, O.; Nakai, H.; Klene, M.; Li, X.; Knox, J. E.; Hratchian, H. P.; Cross, J. B.; Adamo, C.; Jaramillo, J.; Gomperts, R.; Stratmann, R. E.; Yazyev, O.; Austin, A. J.; Cammi, R.; Pomelli, C.; Ochterski, J. W.; Ayala, P. Y.; Morokuma, K.; Voth, G. A.; Salvador, P.; Dannenberg, J. J.; Zakrzewski, V. G.; Dapprich, S.; Daniels, A. D.; Strain, M. C.; Farkas, O.; Malick, D. K.; Rabuck, A. D.; Raghavachari, K.; Foresman, J. B.; Ortiz, J. V.; Cui, Q.; Baboul, A. G.; Clifford, S.; Cioslowski, J.; Stefanov, B. B.; Liu, G.; Liashenko, A.; Piskorz, P.; Komaromi, I.; Martin, R. L.; Fox, D. J.; Keith, T.; Al-Laham, M. A.; Peng, C. Y.; Nanayakkara, A.; Challacombe, M.; Gill, P. M. W.; Johnson, B.; Chen, W.; Wong, M. W.; Gonzalez, C.; Pople, J. A. Gaussian 03, revision B.3; Gaussian, Inc.: Pittsburgh, PA, 2003.

(27) Kim, A.; Filler, M. A.; Kim, S.; Bent, S. F. J. Phys. Chem. B 2005, $109,19817$.

(28) Andersson, M. P.; Uvdal, P. J. Phys. Chem. A 2005, 109, 2937.

(29) Widjaja, Y.; Mysinger, M. M.; Musgrave, C. B. J. Phys. Chem. B 2000, 104, 2527.

(30) Widjaja, Y.; Musgrave, C. B. Surf. Sci. 2000, 469, 9. 